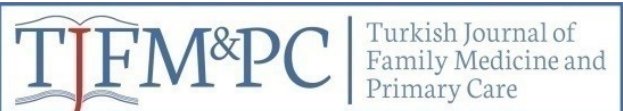

Original Article/Özgün Araştırma

\title{
Usability of Hematologic Parameters in Primary Care to Show Disease Activity in Patients with Ankylosing Spondylitis
}

\author{
Ankilozan Spondilit Hastalarında Hastalık Aktivitesini Göstermede Hematolojik \\ Parametrelerin Birinci Basamakta Kullanılabilirliği
}

Ayşe Nur Topuz ${ }^{1 *}$ Ipek Türk ${ }^{2}$

\begin{abstract}
Introduction: Ankylosing spondylitis (AS) is a type of chronic inflammatory arthritis resulting in ankylosis of the spine and inflammation of the tendons. In this study, we aimed to investigate the usability of hematologic parameters to determine disease activity in AS patients. Materials and Methods: A total of 65 patients who were previously diagnosed with AS were enrolled retrospectively in the current study. Patients were divided into two groups according to their Bath Ankylosing Spondylitis Disease Activity Index (BASDAI) scores. Thirty-one patients who had BASDAI score $>5$ served as "active AS" and 34 patients who had BASDAI score $<5$ served as "inactive AS". Patients data including their physical examination findings were recorded. Medications, demographic properties, and laboratory findings of the patients were also recorded. Results: The clinical and demographic features of both groups were comparable. There were no differences between groups according to the use of medications, the duration of AS and the presence of uveitis, enthesopathy, and peripheral arthritis. In laboratory findings, the Erythrocyte Sedimentation Rate (ESR), C-reactive Protein (CRP) and Neutrophil/Lymphocyte Ratio (NLR) were significantly higher, Mean Platelet Volume (MPV) was significantly lower in active AS group than in inactive AS group. In the correlation analysis, BASDAI score had a significantly negative correlation with MPV $(\mathrm{r}=-0.309, \mathrm{p}=0.012)$ and significantly positive correlations with ESR, CRP and $\mathrm{N} / \mathrm{L}$ values $(\mathrm{r}=0.427, \mathrm{p}<0.001, \mathrm{r}=0.328, \mathrm{p}=0.008$ and $\mathrm{r}=0.316, \mathrm{p}=0.010$, respectively). In linear regression analysis , only MPV score was found to be a predictor for AS activity $(\mathrm{p}<0.04)$.Conclusion: Mean platelet volume is significantly negative correlated with BASDAI score and could provide a clue for primary care physician which patients who are at high risk for AS activity.
\end{abstract}

Key Words: Ankylosing spondylitis, BASDAI score, neutrophyl/lymphocyte ratio, mean platelet volume, primary care

ÖZET

Giriş: Ankilozan spondilit (AS) omurgada ankiloza yol açan ve tendonlarda inflamasyon oluşturan kronik inflamatuvar artrit çeşididir. Bu çalışmada, AS hastalarında hastalık aktivitesini göstermede hematolojik parametrelerin kullanılabilirliğini araştırdık. Gereç ve Yöntem: Çalışmaya daha önce AS tanısıyla takip edilen toplam 65 hasta retrospektif olarak dahil edildi. Hastalık aktivitesini gösteren Bath Ankylosing Spondylitis Disease Activity Index (BASDAI) skoruna göre hastalar iki gruba ayrıld. BASDAI skoru $>5$ olan toplam 31 hasta aktif AS ve BASDAI skoru $<5$ olan toplam 34 hasta inaktif AS olarak ayrıldı. Detaylı fizik muayene bulguları da olmak üzere tüm hastaların verileri kaydedildi. Ayrıca hastaların ilaç kullanımları, demografik ve laboratuvar verileri kaydedildi. Bulgular: Her iki grup klinik ve demografik özellikler açısından benzerdi. Ayrıca ilaç kullanım öyküsü, hastalık yaşı, üveit varlığı, entesopati varlığı ve periferik artrit varlığı açısından da iki grup arasında istatiksel fark saptanmadı. Aktif AS grubunda Eritrosit Sedimentasyon Hızı (ESH), C-reaktif Protein (CRP) ve Nötrofil/Lenfosit oranı (NLR) inaktif AS grubuna göre belirgin olarak yüksek, Ortalama Platelet Hacmi (OPH) ise belirgin olarak düşük saptand. Korelasyon analizinde BASDAI skoru OPH ile belirgin negatif $(\mathrm{r}=-0,309, \mathrm{p}=0,012)$, ESH, CRP ve NLR ile belirgin pozitif korelasyona sahipti (sırasıyla, $\mathrm{r}=0,427, \mathrm{p}<0,001, \mathrm{r}=0,328, \mathrm{p}=0,008$ ve $\mathrm{r}=0,316, \mathrm{p}=0,010$ ). $\mathrm{Bu}$ değişkenler lineer regresyon analizine sokulduğunda sadece OPH' nin AS hastalık aktivitesini predikte ettiği saptandı $(\mathrm{p}<0,04)$. Sonuç: OPH hastalık aktivitesini gösteren BASDAI skoru ile belirgin şekilde negatif ilişkilidir ve birinci basamak aile hekimleri için hangi hastaların AS aktivitesi için yüksek riskli olduğuna dair bir ipucu sağlayabilir.

Anahtar Kelimeler: Ankilozan spondilit, BASDAI skoru, Nötrofil/Lenfosit oranı, ortalama Platelet Hacmi, birinci basamak Received Date: 13.09-2019, Accepted Date: 27.12-2019

*1 District Health Directorate of Cukurova, Family Medicine, Adana, Turkey

Cukurova Universty Medicine Faculty, Department of Rheumatology, Adana, Turkey

Address for Correspondence / Yazışma Adresi: Ayşe Nur Topuz, District Health Directorate of Cukurova, Family Medicine, Adana,

Turkey. E-mail: akca.topuzaysenur@gmail.com

Ayşenur T., İpek T.. Usability of Hematologic parameters in primary care to show disease activity in patients with ankylosing spondylitis TJFMPC, 2020;14 (1): 96-102.

DOI: $10.21763 /$ tjfmpc. 693138 


\section{GíRiş}

İnflamatuar artritin en yaygın nedenlerinden birisi olan Ankilozan Spondilit (AS) (tahmini prevelansı \% 0,1-0,9) genç erişkinleri daha s1k etkileyen kronik inflamatułar romatizmal bir hastalıktır. Öncelikle sakroiliak eklemleri ve daha sonra kademeli olarak omurgayı etkileyen AS, uvea, barsaklar, cilt, akciğerler, böbrekler ve nadiren de kalbi etkileyen ekstra eklem tutulumu olan bir hastalıktır. ${ }^{1}$

Ankilozan spondilit hastalarında sakatlığa ve artmış mortaliteye yol açan temel belirleyici ve birincil altta yatan mekanizma inflamasyondur. ${ }^{2}$ Nötrofil, lenfosit ve trombosit sayıları hemogram ile kolayca elde edilebilir ve bu parametrelerden elde edilen nötrofil/lenfosit ve platelet/lenfosit oranları gibi parametrelerin sistemik inflamasyonun bir belirteci olarak kullanılabileceğini gösteren çalışmalar mevcuttur. ${ }^{3}$ Nötrofiller dolaşımdaki bağışıklık hücrelerinin ana fraksiyonudur ve infeksiyon ve iltihaplanma alanlarında hızla birikir. Trombositler ise başlıca hemostaz, inflamasyon ve bağışıklıkta önemli bir rol oynamaktadır. Öte yandan trombosit fonksiyonu ve aktivasyonunun bir işareti olarak kabul edilen ortalama platelet hacmi (OPH), sepsis, koroner arter hastalığ 1 ve kronik inflamatuvar hastalıkta artmıss morbidite ve mortalite ile ilișkilidir. ${ }^{4,5}$

Bath Ankilozan Spondilit Hastalık Aktivitesi İndeksi (Bath Ankylosing Spondylitis Disease Activity Index) (BASDAI) skoru AS'de hastalık aktivitesi için kullanılan skorlamalardan birisidir. Bu skorlamada subjektif klinik faktörleri içeren parametreler mevcuttur. ${ }^{6} \mathrm{Biz}$ bu çalışmada birinci basamakta kolayca ulaşılabilen ve ucuz yöntemler olan nötrofil-lenfosit oranı (NLO) ve OPH gibi parametrelerin AS hastalarında BASDAI skoru ile ilişkisini ve hastalık aktivitesini ön görebilirliklerini araştırdık.

\section{GEREC ve YÖNTEM}

Çalışmaya daha önce AS tanısı almış ve fizik tedavi polikliniğinde kayıtll, demografik özellikler, ilaç kullanım ve mevcut AS ek özellikleri açısından (hastalık yaşı, üveit varlığı, entesopati varlığı ve periferikartrit varlığ1 gibi) benzer olan toplam 65 hasta retrospektif olarak dahil edildi. Her hastanın arşivde kayıtlı dosyası incelenerek yaş, cinsiyet, vücut ağırlığı ve boy gibi demografik verilerine ek olarak son kontrollerindeki laboratuvar parametreleri ve BASDAI skoru kaydedildi. Ayrıca çalışma hastalarının, artrit öyküsü, yeni veya eşzamanlı infeksiyon kayıtları, ilaçları ve fizik muayene bulguları kayıt altına alındı. Çalışmaya ait protokol yerel etik kurul tarafindan onaylandi.

Anemi dışındaki hematolojik bozuklukları olan, kronik infeksiyöz hastalığa sahip olan hastalar, ülseratif kolit, kronik/akut karaciğer veya böbrek hastalığı olanlar, diabetes mellitus, bilinen kardiyovasküler hastalıkları olanlar ve kanser öyküsü olan hastalar çalışma dışı bırakıldı.

Kayıtlı hasta dosyaları üzerinden laboratuvar parametrelerine ulaşıldı. Hemogram verileri (nötrofiller, lenfositler, monositler, eozinofiller ve bazofiller), sedimantasyon hızı, C Reaktif Protein (CRP), hepatik ve böbrek fonksiyon testleri, lipid profili gibi biyokimyasal parametreler kaydedildi. N / L oranı nötrofil değerini lenfosit sayısına bölerek sayısal olarak hesaplandı.

İstatistiksel analiz: İstatistiksel analizler SPSS 15 programı ile yapıldı. Sürekli değişkenler ortalama \pm Standard sapma (SS) ve kategorik değişkenler yüzde olarak ifade edilmiştir. Değişkenlerin dağılımı Kolmogorov Smirnov testi ile değerlendirildi. Kategorik ve sayısal değişkenleri ki-kare testi, Student t-testi veya varyans testinin analizi ile karşılaştırıldı. NLR ve OPH' nın BASDAI ile ilişkisi ve diğer çalışma parametreleri ile olan ilişkisi Pearson korelasyon testi ile değerlendirildi. Hastalık aktivitesini öngörebilme açısından lineer regresyon analizi kullanıldı. P değerinin $<0,05$ olması anlamlı kabul edildi.

\section{BULGULAR}

Her iki gruba ait klinik ve demografik özellikler, ilaç kullanım öyküsü, AS bulunma süresi, üveit varlığı, entesopati varlığ periferikartrit varlığı gibi değişkenler Tablo 1' de listelenmiştir. Demografik özellikler ve AS bulunma süresi, üveit varlığı, entesopati varlığı ve periferik artrit varlığı gibi ek patolojiler açısından benzer olan grupların ortalama BASDAI skoru aktif AS grubunda $7.6 \pm 1.2$ ve inaktif AS grubunda 2.7 \pm 1.5 olarak bulundu $(\mathrm{p}<0.001)$ (Tablo 1$)$. 
Tablo 1. Çalışma gruplarının demografik ve laboratuvar özellikleri

\begin{tabular}{|c|c|c|c|c|}
\hline \multicolumn{2}{|l|}{ 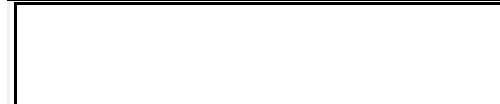 } & $\begin{array}{l}\text { Aktif AS } \\
(n=31)\end{array}$ & $\begin{array}{l}\text { İnaktif AS } \\
(n=34)\end{array}$ & p değeri \\
\hline \multicolumn{2}{|l|}{ Yaş, yıl } & $42 \pm 11$ & $43 \pm 10$ & 0.78 \\
\hline \multicolumn{2}{|c|}{ Cinsiyet, $\mathbf{K} / \mathbf{E}, \mathbf{n}$} & $15 / 16$ & $19 / 14$ & 0.48 \\
\hline \multicolumn{2}{|c|}{ Hastalık süresi, yıl } & $5.7 \pm 3.2$ & $5.6 \pm 2.7$ & 0.90 \\
\hline \multicolumn{2}{|l|}{ Üveit, n } & 4 & 1 & 0.13 \\
\hline \multicolumn{2}{|c|}{ Periferik arterit, $n$} & 3 & 2 & 0.56 \\
\hline \multicolumn{2}{|c|}{ Entesopati, $n$} & 3 & 3 & 0.90 \\
\hline \multirow[t]{3}{*}{ İlaçlar, n } & Anti-TNF & 15 & 16 & 0.91 \\
\hline & Sulfosalazin & 7 & 7 & 0.84 \\
\hline & Mtx & 1 & 1 & 0.94 \\
\hline \multicolumn{2}{|c|}{ Eklem tutulumlu hasta sayısı, n } & 3 & 2 & 0.40 \\
\hline \multicolumn{2}{|c|}{ BASDAI skoru } & $7.6 \pm 1.2$ & $2.7 \pm 1.5$ & $<0.001$ \\
\hline \multicolumn{5}{|c|}{ Laboratuvar bulguları } \\
\hline \multicolumn{2}{|c|}{ Kreatin, mg/dL } & $0.7 \pm 1.6$ & $0.6 \pm 0.1$ & 0.10 \\
\hline \multicolumn{2}{|c|}{ C-reaktif protein, $\mathrm{mg} / \mathrm{dl}$} & $7.2 \pm 5.2$ & $1.7 \pm 1.2$ & 0.003 \\
\hline \multicolumn{2}{|c|}{ Sedimentasyon, (mm/s) } & $43 \pm 31$ & $23 \pm 17$ & 0.002 \\
\hline \multicolumn{2}{|c|}{ Hemoglobin, g/dl } & $13.0 \pm 1.6$ & $13.2 \pm 1.2$ & 0.68 \\
\hline \multicolumn{2}{|c|}{ 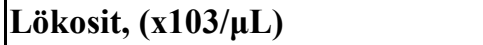 } & $8.2 \pm 1.6$ & $7.5 \pm 1.8$ & 0.12 \\
\hline \multicolumn{2}{|c|}{ 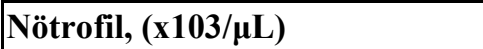 } & $6.6 \pm 1.8$ & $5.2 \pm 1.9$ & 0.004 \\
\hline \multicolumn{2}{|c|}{ Lenfosit, $(\times 103 / \mu L)$} & $2.2 \pm 0.6$ & $2.4 \pm 0.8$ & 0.26 \\
\hline \multicolumn{2}{|c|}{ Trombosit, $(x 103 / \mu L)$} & $315 \pm 81$ & $270 \pm 56$ & 0.008 \\
\hline \multicolumn{2}{|l|}{ N/L oranı } & $3.2 \pm 1.2$ & $2.3 \pm 0.9$ & 0.004 \\
\hline \multicolumn{2}{|c|}{ OPH, (fL) } & $7.6 \pm 0.6$ & $8.7 \pm 2.3$ & 0.016 \\
\hline
\end{tabular}

AS: Ankilozan Spondilit, K/E: Kadın/Erkek, Anti-TNF: Anti Tümor Nekroz Faktör, Mtx: Metotreksat, BASDAI: Bath Anklyosing Disease activity Scoring, NL oranı: Nötrofil/Lenfosit oranı, OPH: Ortalama Platelet Hacmi. İstatiksel analiz için bağımsız t-test kullanıldı ve p $<0.05$ anlamlı olarak kabul edildi. 


\begin{tabular}{|c|c|c|}
\hline & $\mathbf{r}$ & p değeri \\
\hline Yaş & 0.04 & 0.71 \\
\hline Hastalık süresi & 0.004 & 0.97 \\
\hline Sedimentasyon hızı & 0.427 & $<0.01$ \\
\hline C-reaktif protein & 0.328 & 0.08 \\
\hline Lökosit sayısı & 0.02 & 0.86 \\
\hline Nötrofil saysı & 0.325 & 0.08 \\
\hline Lenfosit saysı & -0.108 & 0.39 \\
\hline Trombosit saysı & 0.215 & 0.08 \\
\hline N/L oranı & 0.310 & 0.01 \\
\hline OPH & $\mid-0.309$ & 0.01 \\
\hline
\end{tabular}

BASDAI: Bath Anklyosing Disease activity Scoring, NL oranı: Nötrofil/Lenfosit oranı, OPH: Ortalama Platelet Hacmi. İstatiksel analiz için Pearson korelasyon analizi kullanıldı ve $\mathrm{p}<0.05$ anlamlı olarak kabul edildi.

Laboratuvar bulgularında, beklenildiği üzere Eritrosit sedimentasyon hızı (ESH), CRP ve N/L oranı aktif AS hastalarında inaktif AS hastalarına göre belirgin olarak yüksek bulundu (sirasıyla, $43 \pm$ 31 vs $23 \pm 17 ; \mathrm{p}=0,002,7.2 \pm 5.2$ vs $1,7 \pm 1,2$ $\mathrm{p}=0,003,3,2 \pm 1,2$ vs $2,3 \pm 0,9, \mathrm{p}=0,004)$. $\mathrm{OPH}$ ise düşük saptand $1 \quad(7,6 \pm 0,6 \quad$ vs $8,7 \pm 2,3, \mathrm{p}=0,016$ ) (Tablo 1).

Tablo 2' de BASDAI skoru ile çalışma parametreleri arasındaki korelasyon analizi sonuçları gösterilmektedir. Korelasyon analizinde BASDAI skoru OPH ile belirgin negatif ( $\mathrm{r}=-0,309$, $\mathrm{p}=0,012)$ ve $\mathrm{ESH}, \mathrm{CRP}$ ve $\mathrm{N} / \mathrm{L}$ oran1 ile belirgin pozitif korelasyona sahip olduğu saptand1 (sirasiyla, $\mathrm{r}=0,427, \mathrm{p}<0,001, \mathrm{r}=0,328, \mathrm{p}=0,008$ ve $\mathrm{r}=0,316, \mathrm{p}=0,010)$ (Tablo 2).

$\mathrm{Bu}$ değişkenlerden yaş, sedimentasyon hızı, CRP, N/L oranı ve OPH lineer regresyon analizi ile incelendiğinde sadece $\mathrm{OPH}$ skorunun AS'de hastalık aktivitesini öngördürdüğü saptandı $(\mathrm{p}<0,04)$ (Tablo 3).

\begin{tabular}{|c|c|c|c|}
\hline & $\boldsymbol{\beta}$ & $\mathbf{t}$ & p değeri \\
\hline Yaş, yil & -0.71 & -0.642 & 0.52 \\
\hline Sedimentasyon, $(\mathbf{m m} / \mathbf{s})$ & 0.23 & 1.85 & 0.06 \\
\hline C-reaktif protein, $\mathrm{mg} / \mathrm{dl}$ & 0.20 & 1.66 & 0.10 \\
\hline N/L oranı & 0.16 & 1.32 & 0.19 \\
\hline OPH & -0.23 & -2.03 & 0.04 \\
\hline
\end{tabular}

AS: Ankilozan Spondilit, NL oranı: Nötrofil/Lenfosit oranı, OPH: Ortalama Platelet Hacmi. İstatiksel analiz için lineer regresyon analizi kullanıldı ve $\mathrm{p}<0.05$ anlamlı olarak kabul edildi. 


\section{TARTISMA}

Çalışmamızda AS hastalarının hastalık aktivitesini gösteren BASDAI skoru ile temel laboratuvar parametrelerinden olan ve inflamasyon belirteci olarak kabul edilen N/L oranı ve OPH' nın anlamlı ilişkili oldukları ve OPH' nın hastalık aktivitesini önördürebileceği saptanmıştır. Literatürde BASDAI skoru ile çeşitli inflamatuvar belirteçler AS hastalarında değerlendirilmiş ve BASDAI skorunun inflamasyon ile iç içe olduğu saptanmıştır. Örneğin Gupta ve arkadaşları ateroskleroz öncülü olan intima-media kalınlığının AS hastalarında yüksek olduğunu ve aktivite indeksleri ile korele olduklarını göstermişlerdir.7 Diğer yandan başka bir çalışmada Boyraz ve ark. inflamasyon ile ilintili olan epikardiyal yağ dokuyu AS hastalarında incelemişler ve yağ doku kalınlığını AS hastalarında yüksek bulmuşlardır. Öte yandan çalışmada N/L oranının epikardiyal doku kalınlığı ve aktivite indeksi ile bağlantılı olmadığı bulunmuştur.8Bunun nedeni olarak kısıtlı hasta sayısı bildirilmiştir. Koçer ve arkadaşları 2014 yılında toplam 37 AS tanılı hastayı kontrol grubu ile karşılaştırmışlar ve AS hastalarında kontrol grubuna göre artmış OPH ve azalmış trombosit sayısı bulmuşlardır. Bu çalışmada ayrıca aktif hastalığa sahip 16 hasta AS grubu içinde karşılaştırıldığında hastalığı aktif olanlarda bizim çalışmamız sonuçlarına benzer şekilde OPH daha da düşük bulunmuştur.9 Çalışmamız farklı olarak hasta sayısı açısından daha fazla popülasyon ile incelenmiş ve ayrıca hastalık süresi başta olmak üzere aktif hastalığı olan ile olmayan grup homojenize edilerek çalışmaya dahil edilmiştir.

Günümüzde inflamasyon belirteci olarak kabul edilen N/L oranı tam kan sayımından elde edilen ve mutlak nötrofil ve lenfosit sayımlarından türetilen bir belirteçtir. $\mathrm{Bu}$ basit oranın çeşitli sistemik hastalıklarda inflamasyonda kullanılabilirliği çok sayıda çalışma ile gösterilmiştir.5-7 Literatürde mevcut olan AS aktivitesinin inflamasyon ile ilişkisi çalışmamızda BASDAI skoru yüksek olan aktif AS hastalarında artmış inflamatuvar parametreler ve artmış NL oranı ile teyit edilmiştir. Literatüre ek olarak çalışmamızda OPH 'nin aktif AS hastalarında değiştiğini gözlemledik. Çalışmamız sonucunda AS hastalarının aktivitesini değerlendirmede birinci basamakta ucuz, kolay ve ulaşılabilir temel kan parametrelerinin kullanılabilir olduğu saptanmış olup yukarıda bahsedilen çalışmaya ek olarak regresyon analizinde hastalık aktivitesini öngörüp görmediği araştırılmış ve OPH ' nın hastalık aktivitesini yansitabileceği bulunmuştur. $\mathrm{Bu}$ bağlamda $\mathrm{OPH}$ ve N/L oranı gibi parametrelerin AS hastalarında BASDAI skoru ile ilişkili olduğu ve ayrıca OPH 'nın özellikle birinci basamakta görevli hekimlere AS aktivitesi için fikir verici bir parametre olabileceği gösterilmiştir.

Çalışma sonuçları doğrultusunda elde edilen artmış aktivite ile N/L oranı ve $\mathrm{OPH}$ arasındaki ilişkiler bazı teoriler ile açıklanabilir. Artmış nötrofil ve dolayısıyla N/L oranı AS gibi inflamatuvar özellikli eklem hastalıklarının patogenezinde artmış sitokinler ve IL-, IL-6, IL-7, IL-8, IL-12 VE IL-13 gibi interlökin seviyelerindeki artış ile açıklanabilir.10Aslında inflamatuvar hastalıklarda N/L oranında değişimin esas nedeni de bu interlökinler arasındaki dengenin değişimidir. Nötrofil apopitozu üzerine etkili olan IL-4 ve 5 gibi sitokin seviyelerinde artış başta RA gibi inflamatuvar özellikteki eklem rahatsızlıklarında gösterilmiştir.11 Ayrıca AS etiyopatogenezinde rol alan IL-23 gibi interlökinlerin nötrofil sayısı üzerine etkisi olabilir. 12

OPH düzeyleri ülseratif kolit, Crohn hastalığ 1 , sistemik lupus eritematozus ve romatoid artrit gibi birçok inflamatuvar hastalıkta incelenmiştir.13,14 $\mathrm{Bu}$ çalışmalarda yüksek ve düşük dereceli inflamatuvar hastalıklarda, OPH değerlerinin sistemik enflamasyonun yoğunluğuna bağlı olarak değiştiği, ancak sonuçların çelişkili olduğu saptanmıştır. Kısacık ve ark.'nın yaptıkları çalışmada tedavi almayan, yüksek BASDAI skoru ve yoğun inflamatuvar yanıta sahip AS'li hastaların OPH değerlerinin daha düşük olduğu saptanmış, öte yandan OPH ile hastaların BASDAI skorları arasında anlamlı bir ilişki tespit edilememiştir.15Ortalama platelet hacminin BASDAI skoru ile negatif ilişkili olması ise birkaç mekanizma ile açıklanabilir. Trombositler dinamik bir yapı ve fonksiyona sahiptir. Öyle ki, fizyolojik ve patolojik sinyaller trombositlerin aktivasyonuna neden olmaktadır. Özellikle inflamatuvar durumlarda trombositler uyarılmakta ve yapılarında ve fonksiyonlarında önemli değişiklikler gelişmektedir. Romatoid artrit gibi inflamasyon 
yanıtının arttığı hastalarda OPH düzeylerinin düşük olduğu daha önceki çalışmalarda gösterilmiş ve bu durumun trombositlerin inflamasyon alanındaki (damar duvarı ve sinoviyal membranlar) yoğun tüketiminden kaynaklanabileceği bildirilmiştir. $\mathrm{Bu}$ düşüklük akut dönemde kullanıma bağlı olabilir. Büyük hacimli trombositlerin inflamasyon bölgesine göç ederek bu bölgelerde tüketildiği, buna sekonder olarak trombosit yapımının uyarılarak dolaşımdaki trombosit sayısının arttığı inflamatuvar hastalıklarda görüldüğü bildirilmiştir. Büyük trombositler daha reaktiftirler; küçük trombositlere göre granül içerikleri daha yoğun olduğundan, daha fazla sitokin ve tromboksan A2 üretirler ve enflamasyonun akut evresinde bunlara ihtiyaç artar.16 Ek olarak pro-inflamatuar sitokinlerin ve akut faz reaktanlarının fazla üretimi megakaryopoiezis sürecini etkileyerek, kemik iliğinden küçük hacimli trombositlerin salınmasına ve böylece trombosit büyüklüğünün azalmasına sebep olabileceği de ileri sürülmüştür.17Proenflamatuar sitokinlerden, özellikle interlökin-6 (IL-6) inflamatuvar artritlerin patogenezinde önemli rol oynamaktadır.1820Trombosit sayısı ile OPH arasında gözlenen bu ters ilişki, dolaşımdaki trombosit kütlesini sabit tutarak fizyolojik ve birçok patolojik durumda hemostazı sağlamayı amaçlamaktadır.21Trombosit sayısı ile OPH arasındaki ters ilişki ayrıca, defektif trombopoiezis, artmış yıkım ve dolaşımdaki trombositlerin reaktif maddelerden zengin ortamda şişmesi gibi durumlardan da etkilenebilir. Yapılan daha önceki çalışmalardan birinde trombosit sayısı ile OPH arasındaki ilişkinin çoklu ve değişken faktörler tarafindan ve birbirinden bağımsız olarak etkilenmesine bağlanmıştır.22Çalışmamızda benzer şekilde aktif AS olan hastalarda inaktif AS hastalarına göre artmış platelet sayısı ve azalmış OPH değeri bulunmuştur. Ek olarak biz bu çalışmada AS hastalarında BASDAI skoru ile OPH arasında belirgin bir negatif yönde ilişki olduğunu ve regresyon analizinde AS hastalık aktivitesini BASDAI skoru gibi yansıtabileceğinin saptadık. Bu açıdan çalışma verilerimiz kronik süreçli inflamatuvar bir hastalık olan AS' de hemogram parametrelerinin ilişkisinin yanı sıra hastalarda hastalık aktivitesini belirlemek için kullanılan BASDAI skoru ile olan ilişkisini de incelemiştir.

Hasta sayısının az olması çalışmamızın en büyük kısıtlılığıdır. Ayrıca çalışmamız retrospektif olup daha geniş katılımcı ile prospektif dizayna sahip çalışmalar ile desteklenmelidir. Son olarak, mevcut kayıtlar doğrultusunda bakabildiğimiz verilere ek olarak daha objektif sonuçlar için interlökin gibi diğer inflamatuvar belirteçler eklenebilir.

\section{SONUÇ}

BASDAI skoruna alternatif olarak, N/L oranı ve OPH gibi bulunabilir, düşük maliyet ve değişimli aktivite ile iyi korelasyon gibi avantajları olan parametreler birinci basamakta aile hekimleri için AS aktivitesi açısından yüksek riskli hastaları saptamaya dair bir ipucu sağlayabilir.

\section{KAYNAKLAR}

1. El Maghraoui A. Extraarticularmanifestations of ankylosingspondylitis: prevalence, characteristics and therapeuticimplications. Eur J InternMed 2011; 22:554-60.

\section{Zochling J, Braun J. Mortality in} rheumatoid arthritis and ankylosing spondylitis. ClinExpRheumatol 2009;27:127-130.

3. Boyraz I, Koç B, Boyacı A, Tutoğlu A, Sarman H, Ozkan H. Ratio of neutrophil/lymphocyte and platelet/lymphocyte in patient with ankylosing spondylitis that aretreating with anti-TNF. Int J ClinExpMed 2014; 7:2912-5.

4. Garrett S, Jenkinson T, Kennedy LG, Whitelock H, Gaisford P, Calin A. A new approach to defining disease status in ankylosing spondylitis: the Bath Ankylosing Spondylitis Disease Activity Index. J Rheumatol. 1994; 21(12): 228691.

5. Torun S, TuncBD, Suvak B, et al. Assessment of neutrophil lymphocyte ratio in ulcerative colitis: A promising marker in predicting disease severity. ClinResHepatolGastroenterol 2012;36(5):491-497.

6. TamhaneUU, Aneja S, Montgomery D, Rogers EK, EagleKA, Gurm HS. Association between admission neutrophil to lymphocyte ratio and outcomes in patients with acute coronary syndrome. Am J Cardiol 2008;102(6):653-657. 19.

7. Gupta N, Saigal R, Goyal L, Agrawal A, Bhargava R, Agrawal A. Carotid intima media 
thickness as a marker of atherosclerosis in ankylosing spondylitis.Int J Rheumatol. 2014;2014:839135. doi: 10.1155/2014/839135.

8. Boyraz I, Onur Caglar S, Erdem F, Yazici M, Yazici S, Koc B, Gunduz R, Karakoyun A. Assessment of relation between neutrophil lympocyte, platelet lympocyte ratio sandepicardial fatthickness in patients with ankylosing spondylitis. MedGlas (Zenica). 2016 Feb 1;13(1):14-7. doi: 10.17392/832-16.

9. Kocer D, Sarıüzel FM, Güler E, Karakükcü Ç, Sütbeyaz ST, Gödekmerda A. MPV Değerinin AnkilozanSpondilitli Hastalarda Enflamasyon Belirteci Olarak Değerlendirilmesi. Türk Klinik Biyokimya Derg 2014; 12(2): 73-77.

10. Kantola T, Klintrup K, VayrynenJP, et al. Stage-dependentalterations of the serum cytokinepattern in colorectalcarcinoma. Br J Cancer 2012;107(10):1729-1736.

11. Cascao R, RosarioHS, Souto-Carneiro MM, Fonseca JE. Neutrophils in rheumatoidarthritis: Morethansimplefinaleffectors. AutoimmunRev 2010;9(8):531-535.

12. SherlockJP, Buckley CD, CuaDJ. Thecritical role of interleukin23 in spondylo arthropathy.MolImmunol 2014;57(1):38-43.

13. MorrellCN, Aggrey AA, ChapmanLM, ModjeskiKL. Emerging roles for platelets as immune and inflammatorycells. Blood. 2014; 123 : 2759-2767. https://doi.org/10.1182/blood-2013-11462432 PMID: 24585776; PubMed Central PMCID: PMCPMC4007605.

14. SempleJW, Italiano JE Jr, Freedman J. Platelet sandtheimmunecontinuum. NatRevImmunol. 2011; 11: 264-274. https://doi.org/10.1038/nri2956 PMID: 21436837.

15. Kisacik B, Tufan A, Kalyoncu U, Karadag O, Akdogan A, OzturkM.A, et al. Meanplatelet volüme (MPV) as an inflammatory marker in ankylosing spondylitis and rheumatoidarthritis. Joint Bone Spine 2008; 75(3): 291-294.

16. Gasparyan AY, Sandoo A, Kalinoglou AS, Kitas GD. Mean platelet volume in patients with rheumatoid arthritis: theeffect of anti-TNFalphatherapy. RheumatolInt 2010; 30(8): $1125-$ 1129.
17. Bath PM, ButterworthRJ. Platelet size: measurement, physiologyandvasculardisease. Blood CoagulFibrinolysis 1996; 7(2): 157-61.

18. BerteroMT, Caligaris-Cappio F. Anemia of chronicdisorders in systemic autoimmune diseases. Haematologica 1997; 82(3): 375-81.

19. Ertenli I, Kiraz S, OzturkMA, Haznedaroğlu IC, Celik I, Calgüneri M. Pathologic thrombopoiesis of rheumatoidarthritis.

RheumatolInt 2003(2); 23: 49-60.

20. Nishimoto N. Interleukin-6 in rheumatoid arthritis. CurrOpinRheumatol 2006; 18(3): 277-81.

21. ThompsonCB. From precursortoproduct: how do megakaryocytes produce platelets? ProgClinBiolRes 1986; 215: 361-71.

22. ThompsonCB, JakubowskiJA. The pathophysiology and clinical relevance of platelet heterogeneity. Blood 1988; 72: 1-8. 